\title{
AUTOGESTÃO E DISCURSOS NEOLIBERAIS NA EDUCAÇÃO: O (CON)TEXTO PRÁXIS
}

\author{
Themis Karine Dutra MenegazZI \\ JoACIR MARQUES DA COSTA \\ Universidade Federal de Santa Maria (UFSM), Santa Maria, Rio Grande do \\ Sul, Brasil
}

\begin{abstract}
Resumo: Este trabalho é parte de uma pesquisa desenvolvida ao longo do Curso de Especialização em Gestão Educacional, da Universidade Federal de Santa Maria (UFSM). Além disso, se configura como uma tentativa de releitura da prática de autogestão, a partir do contexto neoliberal atual, com o objetivo de compreender os discursos produzidos acerca de autogestão no contexto do Coletivo Práxis de Educação Popular. O Práxis é um coletivo vinculado à UFSM que atua como movimento social de educação popular e é autogerido pelos seus componentes. Para tanto, foi realizada uma análise discursiva tanto em documentos como o Projeto do Coletivo quanto nas práticas sócio-político-discursivas do coletivo, entendendo o discurso como uma prática construtiva de significação do mundo. Assim, o Práxis se apresenta como uma produção discursiva hibridizada em que a educação e a autogestão são re/significadas frente a uma negociação/disputa discursiva democrática/neoliberal.
\end{abstract}

Palavras-chave: Autogestão. Educação. Neoliberalismo. Práxis.

\section{PRIMEIRAS PALAVRAS}

Este artigo é o recorte de uma pesquisa desenvolvida ao longo do curso de Especialização em Gestão Educacional, do Programa de Pós-Graduação em Políticas Públicas e Gestão Educacional (PPPG), da Universidade Federal de Santa Maria (UFSM), como uma tentativa de releitura da educação popular e de autogestão com o objetivo de compreender os discursos produzidos acerca de educação popular e de autogestão no contexto do Coletivo Práxis de Educação Popular. Neste artigo, abordaremos especificamente a parte sobre autogestão e sua relação com os discursos neoliberais que modelam o contexto no qual o Práxis nasce e se desenvolve.

A história do coletivo que intitula esse trabalho começa em 1999, com uma forma embrionária, na região centro do estado do Rio Grande do Sul, tendo como palco a Universidade Federal de Santa Maria (UFSM) e, como atores, estudantes da mesma instituição, sobretudo de cursos de licenciatura. Em 2000, ele se institucionaliza oficialmente como projeto de extensão da Universidade, é elaborada sua proposta educativa e, então, se assume enquanto um Movimento Social e "como estratégia dos movimentos populares de acesso à educação superior" (ALMEIDA, 2016, p. 13), sendo inspirada pela obra de Paulo Freire e por suas concepções de educação popular. 
O Coletivo Práxis de Educação Popular foi/é formado por estudantes que não aceitavam/aceitam a naturalização de uma universidade hegemonicamente branca, de classe média, composta de alunos provenientes de escolas e/ou cursos particulares. Estudantes que não aceitam a lógica de mercantilização da educação por cursos preparatórios que corroboram para que apenas uma parcela privilegiada da população tenha acesso ao conhecimento. Os alunos são influenciados por uma onda de criação de pré-vestibulares populares por todo o país que se inicia a partir dos anos 90 .

Além disso, o Coletivo se diferencia de outros setores da universidade por possuir autonomia em relação ao órgão, autonomia tanto pedagógica quanto gestionária, de modo que toda sua criação é voltada para um projeto de sociedade com um discurso libertário e emancipatório, ainda que financiado pela universidade e voltado para o ingresso a ela. O Práxis é um coletivo autogestionário e de educação popular ligado a uma instituição. Penso que essa contradição representa por si só o que é estar dentro do jogo discursivo neoliberal no qual o capital se torna central e absorve até os territórios mais afastados e difíceis. Educação, Popular, Trabalho, Anarquia, Movimento Social, são termos que são re/significados na contemporaneidade. São fragmentados, multiplicados, repartidos e distribuídos, adquirindo cada vez novas formas e outras nem tão novas assim.

Deste modo, este trabalho científico se constitui como uma tentativa de releitura da prática de autogestão, a partir do contexto neoliberal atual. Uma releitura baseada no organismo vivo que se constitui o Práxis. No entanto, apesar do que a semântica da palavra remete, não serão utilizados métodos positivistas influenciados pelas ciências naturais, mas sim os métodos fluidos do discurso. Discurso também vivo, sendo produzido e produzindo sujeitos e significações.

Nesse sentido, tem-se como problemática de pesquisa a seguinte indagação: que discurso(s) emerge $(\mathrm{m})$ a partir da práxis de autogestão no contexto do Coletivo Práxis de Educação Popular? Portanto, nosso objetivo geral passa a ser: compreender o(s) discurso(s) produzido(s) acerca de autogestão no contexto do Coletivo Práxis de Educação Popular, considerando o contexto neoliberal atual.

Minha posição nesta pesquisa é de educadora-pesquisadora. "Ensino porque busco, porque indaguei, porque indago e me indago. Pesquiso para constatar, constatando, intervenho, intervindo educo e me educo". (FREIRE, 1996, p. 29). Faço parte do Coletivo desde o segundo semestre de 2018 como educadora de literatura e bolsista. Com isso, minha visão é de alguém que vive a práxis semanalmente, o que me autoriza a falar e analisar, não me abstendo de minhas emoções, mas entendo que elas colaboram para uma análise mais fiel ao que acontece no local, uma vez que sou constantemente afetada pelos discursos a minha volta. Sou produto e produtora a um só tempo.

Assim, o corpus analítico deste trabalho constitui-se a partir de textos fixos, como Projeto do Práxis, e de textos fluídos encontrados na vivência no Coletivo. Ao considerar textos, adoto a visão de Leyla Perrone-Moisés, na qual:

O texto não é discurso de um sujeito imutável e pleno, prévio ou posterior ao discurso, é antes, o lugar onde o sujeito se produz com risco, onde o sujeito é posto em processo e, com ele, toda a sociedade, sua lógica, sua moral, sua economia. (PERRONE-MOISÉS apudSEGOLIN, 1992, p. 31-32). 
Por esta razão, essa pesquisa é viva, constituída de sujeitos. Nesse sentido, o Coletivo Práxis em si é um discurso. Um texto que precisa ser lido em todas suas partes. Espaços, sala de aula, corredores, coordenação, assembleias, aulões, reuniões, relações, contatos, conversas, desentendimentos, relatórios, confraternizações, protestos etc., são todos discursos que significam e, portanto, serão considerados nessa pesquisa quase que, poderíamos dizer, etnográfica.

\section{AUTOGESTÃO, NEOLIBERALISMO E EDUCAÇÃO: ALGUMAS CONSIDERAÇÕES BIBLIOGRÁFICAS}

A partir da Constituição de 1988 (BRASIL, 1988), emergem discursos sobre Gestão Democrática, sendo produzida uma vasta rede de discussões sobre ela. No entanto, a noção de autogestão parece estar marginalizada e silenciada assim como o movimento que a difundiu. Iremos, então, sublinhar algumas questões sobre esse sistema ou nãosistema. Além disso, esboçaremos questões relativas ao contexto neoliberal e suas inscrições nos discursos em educação.

\section{O NASCIMENTO DE UMA NOVA FORMA DE ORGANIZAÇÃO}

A partir do entendimento de que não se supera a dominação dominando, o movimento operário começa, em meados do século XIX, a elaborar a prática de autogestão, com base na seguinte lógica: uma vez que toda organização hierárquica implica em subordinação, certos indivíduos são privados de sua capacidade de tomada de decisões e impedidos de serem sujeitos de suas próprias ações. Àqueles que se encontram no topo da pirâmide, cabe o ato de pensar, de refletir, de inventar e de criar, enquanto os outros são destinados à realização das ideias do outro, reduzidos a instrumentos, a somente mãos que agem, mas que não representam um ser em sua totalidade.

Contra a propriedade privada e contra o poder hierárquico, do mercado ou do Estado, surge o movimento anarquista, principal promotor da ideia de autogestão. Sucumbidos nas condições trabalhistas do século XIX, vivenciando epidermicamente a Revolução Industrial, operários começam a se organizar e a refletir sobre sua posição no mundo capitalista em ascensão. O racionalismo burguês, ironicamente, os leva a perceber que tal "liberdade, igualdade e fraternidade" não se aplicavam a quem não possuísse o poder intrínseco ao dinheiro. Começam a ser construídos, então, os primeiros sindicatos e associações de trabalhadores com ideais populares. Dessas primeiras tentativas de organização, consolidam-se articulações proletárias como o Comunismo e o Anarquismo, ou Socialismo real e Socialismo utópico/libertário. Essa própria denominação já carrega um forte peso ideológico e avaliativo que suscita uma vasta discussão, no entanto, dado os limites da pesquisa, nos concentremos em questões mais superficiais.

De modo bastante objetivo, o que os une é a socialização dos meios de produção de modo igualitário e o fim da propriedade privada. No entanto, o Comunismo aponta o Socialismo (autoritário ou de Estado) como um modelo provisório de gestão social, no qual o poder se encontra nas mãos do Estado, responsável pela distribuição de riquezas, educação, propaganda e expansão do regime para outras regiões até que este possa ser extinto. Rejeitando uma mudança social que perpetua a dominação de um ser humano 
sobre outro, mesmo que provisoriamente, o Anarquismo defende um modelo de organização social autogestionário:

Em todas as épocas e em todos os países, quando, após ter derrubado um governo, o povo submeteu-se a um novo governo ao invés de continuar sua obra de libertação, este governo, para permanecer no poder e impedir que a revolução continue e desenvolva-se, sempre empregou meios de repressão do mesmo tipo ou piores que aqueles utilizados pelo regime derrubado. Os pretensos "tribunais revolucionários" sempre foram injustos, do mesmo modo que os tribunais militares e, a pretexto de defender a "revolução", como os outros para defender a "ordem", dirigiram seus golpes principalmente contra os revolucionários que eram uma ameaça ao poder recentemente constituído (MALATESTA, 2014, p. 216).

Assim, ao contrário do que a manipulação semântica da palavra anarquia faz crer, esta não significa ausência de ordem, mas sim uma ordem que respeita a individualidade de todos os sujeitos e não os aprisiona em regras prontas ditadas por dominantes. Tal ordem nega a necessidade da hierarquia e propõe uma democracia direta, horizontal, em que todos os participantes de uma instituição são responsáveis em igual proporção pela sua administração.

\section{DISCURSOS (NEO) LIBERAIS E EDUCAÇÃO}

Os processos decisórios são criados de modos que se resguardem os direitos individuais, sobretudo o da propriedade privada. Assim, nascem as democracias liberais com o objetivo de que todos os sujeitos de uma sociedade possam participar politicamente de acordo com seus interesses, de modo que as decisões tomadas pelo Estado ganhem legitimidade e sejam seguidas. Essa noção começa a ser incorporada, então, em diferentes setores da esfera pública.

Para muito além de eleições para cargos políticos em uma democracia representativa, a lógica da gestão democrática é incorporada a outros aparelhos do Estado, como a escola. Presente na Lei de Diretrizes e Bases da Educação (BRASIL, 1996) e no Plano Nacional da Educação (BRASIL, 2014), a gestão democrática está prevista no ensino público, visando à participação social e transparência de decisões. A gestão escolar possui, assim, coordenadas consignadas na Constituição de 1988. A nossa Carta Magna preconiza no seu artigo 206, Inciso VI: "o ensino será ministrado, dentre outros, com base no princípio da "gestão democrática do ensino público, na forma da lei" ". A Lei de Diretrizes e Bases da Educação (Lei no 9.394, de 1996) em seu artigo 14 prescreve que a Gestão democrática é a maneira de administrar uma escola de forma que os vários segmentos da comunidade estejam envolvidos, contribuindo com suas peculiaridades para a elaboração das normas de gestão. 
As normas acima citadas reafirmaram e consolidaram uma maior participação dos envolvidos no ambiente escolar, de modo a promover decisões conjuntas, contemplar a eleição de diretores, a criação dos conselhos escolares e elaboração dos Projetos Político Pedagógico (PPP) da escola. Essa mudança de concepção e os instrumentos criados fundamentam-se, assim, nos princípios de descentralização administrativa, participação, flexibilidade, transparência e autonomia de cada escola nas suas decisões. Com isso, essa visão pretende propiciar a cada ambiente escolar analisar suas prioridades e atender às peculiaridades locais em um contexto próprio e singular. Além disso, estimula a interação entre a gestão da escola e seus contextos educacionais, incluindo alunos, pais, professores, funcionários, entre outros, de modo a conectar-se com o mundo atual e afastar o sistema de ensino da estagnação (LUCK, 2000).

No entanto, no seio desse processo contínuo de exercício da democracia, percebe-se a ausência de sujeitos. Ora, sem sujeitos não há democracia. Sem a participação de alunos, pais, professores, comunidade em geral, não há gestão democrática. Contudo, uma questão se abre, havendo essa participação, haveria democracia? Do latim participatio, ōnis, participação significa 'partilha', assim, como incentivar a participação se não há uma real partilha das escolas?

Essa mesma questão segue também para outros âmbitos do Estado. Conforme aponta Dahl (2012), a desigualdade de recursos afeta o processo democrático. Desses recursos podemos entender o capital, o conhecimento e, sobretudo, a posição social em que se encontra um indivíduo. Em uma sociedade hierárquica, por mais que haja uma participação, uma descentralização ou uma tentativa de democratização, ela falha. Essa falha ocorre porque a sentença decisória segue sendo de uma minoria. Uma minoria que decide o que ensinar, para quem e como. Ela falha porque não há participação e, muito menos, a partilha. A escola não é aberta, ela é burocratizada, é imperialista, ou seja, a escola é burguesa.

O tensionamento criado é de que a gestão democrática da escola segue as mesmas falácias da democracia representativa no momento que ela não assume uma postura autogestionária. Ela segue produzindo sensações no aluno de que ele deve estar atento aos problemas políticos e participar do jogo decisório, contudo, sempre restrito em sua posição subalterna na qual outro sujeito o representa nas decisões mais importantes. Nesse processo, o aluno segue sem poder escolher o que aprender, que horas, em que lugar e como deseja. A questão é: há uma gestão democrática quando o aluno, por exemplo, sequer poder ir ao banheiro quando ele deseja?

O simples fato de ser participativo, não torna um sistema político menos coercitivo. Enquanto a maioria tiver a capacidade de impor as suas decisões sobre a minoria, estamos falando de um sistema político idêntico em espírito ao que governa o Brasil hoje - um sistema que também precisaria de prisões, polícia, cobradores de impostos, ou então, outras formas de realizar as mesmas funções. A verdadeira liberdade não é uma questão de quão participativo é o processo de responder perguntas, mas a extensão até onde podemos definir as perguntas nós mesmxs - e a possibilidade de impedirmos que os outros imponham suas respostas sobre nós. (COLETIVO CRIMETHINC, 2017, p. 25). 
Como aponta Bordignon (2009), os indígenas já possuíam um sistema de ensino, no entanto, em um processo de colonização, coube aos jesuítas "levar" a educação até os povos "não-civilizado". Sob uma lógica elitista, colonial, paternalista e centralizadora, foi se constituindo a educação ao longo da história do Brasil. Mais de 500 anos depois da chegada dos portugueses, algumas conquistas foram traçadas em termos de descentralização, autonomia e democratização. "Mas, em alguns momentos de nossa história, a descentralização significou transferência de responsabilidades, omissão e abandono" (BORDIGNON, 2009, p. 19).

Conforme o autor (2009), foi na constituição de 1934 que a educação no país aparece de forma sistêmica. É aprovado, então, um Plano Nacional de Educação, no entanto, algumas rupturas políticas provocam descontinuidades na educação, sendo, na constituição de 1988, instituído o regime de colaboração entre a União, os Estados, o Distrito Federal e os Municípios, assim como seus sistemas de ensino. Desse modo, não há uma relação de subordinação entre os entes, podendo, por exemplo, o município constituir seu próprio sistema de ensino se assim desejar, desde que respeite as normas federais.

A instituição do Sistema por lei municipal explicita e afirma o espaço da autonomia do município e as responsabilidades educacionais próprias. O Sistema tem um caráter de afirmação de princípios e valores mais permanentes na construção da cidadania e da sociedade que se deseja no projeto municipal de educação. Ao assumir, com autonomia, a responsabilidade de suas atribuições prioritárias, o município possibilita a dimensão concreta do exercício do poder local, da cidadania ativa. (BORDIGNON, 2009, p. 38).

O exercício dessa suposta cidadania implica na criação de conselhos e em mais participação da sociedade nas decisões da esfera pública. Nesse processo, muitos interesses privados acabam entrando em jogo, de modo que uma dicotomia entre público/privado se torna nebulosa e fluída. Segundo Bobbio (2018), o direito público nasce muito depois do direito privado, a partir da consolidação do Estado moderno. Em uma concepção liberal de sociedade, são postos em xeque os interesses individuais e os coletivos, com isso, há um grande debate sobre os limites de intervenção estatal. Existem hoje dois processos ocorrendo com base nessa influência mútua dos "dois setores", a publicização do privado e a privatização do público de modo que um reflete os interesses de outro (BOOBIO, 2018).

Além dessas contradições dentro da própria concepção de gestão democrática, a gestão educacional sofre outro ataque. Com o desmonte da URSS, o processo cada vez mais acelerado de globalização, novas tecnologias, multiculturalismos e aparente domínio do capitalismo como modelo econômico mundial, a lógica neoliberal passa a reger não somente a esfera privada, como também a gestão pública, incluindo a educação. O neoliberalismo se torna um modo de vida que ressignifica até mesmo o conceito de liberdade. 
MENEGAZZI, T. K. D.; COSTA, J. M. da

Conforme Giroux, "a liberdade se transformou em sinônimo de interesse próprio desenfreado e em uma racional para abdicar de qualquer senso de responsabilidade moral e política" (FREITAS, 2018, p. 16). Tal concepção difere da noção anarquista de liberdade, na qual esta não é entendida como um fato individual, mas um fato coletivo. Bakunin, um dos maiores representantes do anarquismo no séc. XIX, em um contexto de Associação Internacional dos Trabalhadores e Comuna de Paris, deixa claro em seus escritos sobre liberdade a sua concepção:

Só sou verdadeiramente livre quando todos os seres humanos que me cercam, homens e mulheres, são igualmente livres. A liberdade do outro, longe de ser um limite ou a negação de minha liberdade, é ao contrário, sua condição necessária e sua confirmação. (...) de forma que quanto mais numerosos forem os homens livres que me cercam e quanto mais extensa e ampla for a sua liberdade, maior e mais profunda se tornará minha liberdade. (...) Minha liberdade pessoal, assim confirmada pela liberdade de todos, se estende até o infinito (BAKUNIN, 1999, p. 47/48).

Essa distinção de conceito lexical também nos mostra uma distinção ideológica. Diferente da noção liberal de que a liberdade de um indivíduo vai até onde começa a do outro, a concepção anarquista é de uma liberdade infinita. Há, com isso, uma quebra epistemológica que demostra a incompatibilidade de diferentes projetos de sociedade. Freitas (2018) demonstra em um estudo recente que o neoliberalismo implica em uma sociedade vertical e hierarquizada. Desse modo, a planificação da economia e da sociedade como um todo no projeto socialista representa um medo que acelera e reinventa a lógica liberal até chegar em um autoritarismo social. Ainda, conforme o autor:

Na América Latina, o esgotamento da primeira onda neoliberal nos anos 1990, seguido da ascensão de governos progressistas ocorrida em seguida, criou a ilusão de que o neoliberalismo havia passado. Produziu também um efeito complementar: chamou nossa atenção para o lado das reformas econômicas e seus impactos, retirado a nossa atenção do lado obscuro do neoliberalismo - sua ligação política com os conservadores, seu significado ideológico e os métodos pelos quais se propaga (FREITAS, 2018, p. 14).

Dentre esses métodos, a reforma empresarial da educação ganha um lugar de destaque. A busca por padronização curricular, avaliações em larga escala, sistema de responsabilização, accountability, sistemas de recompensas, competitividade e desenvolvimento de competências são noções que ganham cada vez mais espaço nas políticas educacionais.

O alargamento do campo de estudos dedicado a essa temática alimentou a gradativa imposição e legitimação de um novo vocabulário (centrado em termos como eficiência, mercado, renda, ativos, vulnerabilidade, pobre etc.), em detrimento de outro (como igualdade, exploração, dominação, classe, luta de classe, trabalhador etc.) (PEREIRA, 2014). 
Hoje, há ainda o que se chama de Nova Gestão Pública, que nada mais é que a entrada do setor privado e da Terceira via no setor público. Com isso, a lógica de mercado passa a reger cada vez mais o Estado e a coisa pública. Ao analisar políticas educacionais em todas as etapas da educação básica no Brasil, Peroni (2015) constata diferentes formas de privatização do público. A autora percebe uma redefinição do papel do Estado frente ao contexto neoliberal. Ao passo que há um incentivo do livre-mercado, o Estado também é chamado a intervir no capital produtivo em momentos de crise, assim como a atrair capital financeiro estrangeiro. Em uma política globalizada, acaba por ocorrer um processo de mercadificação da educação pública, definindo também o conteúdo da educação. "Essas mudanças ocorrem através da disseminação de valores e práticas de empreendimento, empreendedorismo e transposição do discurso internacional do gerencialismo" (PERONI, 2015, p. 24).

A autora (2015) questiona, então, as consequências dessa dinâmica para a democratização do ensino brasileiro. Além disso, essa autora aponta que o Estado nasce vinculado aos interesses privados e recentemente tem adotados formas timidamente democráticas e, em uma correlação de forças, o setor privado segue oferecendo parcerias principalmente a partir da precarização do serviço público. Com isso, perpetuam sua proposta através da formação, gestão, monitoramento e avaliação da educação.

\begin{abstract}
Nestas condições, a educação está sendo sequestrada pelo empresariado para atender a seus objetivos de disputa ideológica. A educação vista como um "serviço" que se adquire, e não mais como um direito, deve ser afastada do Estado, o que justifica sua privatização. Do ponto de vista ideológico, a privatização também propicia um maior controle político do aparato escolar, agora visto como "empresa" (FREITAS, 2018, p. 29).
\end{abstract}

Tal debate nos leva a pensar no papel social da universidade. Nas diferentes conferências que levaram ao Fórum Latino-americano sobre Educação Superior em 2014, fica evidente o esforço latino em "inserir a universidade na centralidade das mudanças sociais e econômicas no contexto da pobreza, das desigualdades regionais e da agressão ao meio ambiente (...), inserção da universidade como bem público" (CUNHA, 2015, p. 87). Desse modo, a universidade não poderia estar à mercê de políticas mercadológicas e meritocráticas que focalizam apenas na relação "custo-qualidade-benefício".

Contudo, o Brasil tem enfrentado um turbulento processo político de fortalecimento da direita, no qual ela:

Enxerga a universidade como disfuncional ao modelo neoliberal que não necessita que ela faça pesquisa, em decorrência mesmo da própria condição periférica do país que não demanda conhecimentos localmente gerados. Esta visão da universidade conduz a um pragmatismo das elites que se manifesta com o consequente corte de tudo o que é considerado "desnecessário" e ainda pela pressão sobre salários e condições de trabalho (CUNHA, 2015, p. 91). 
Tudo isso se reflete nos cortes de verbas, bolsas de pesquisa, assistência estudantil que vem ocorrendo no ano de 2019, causando um futuro de incerteza sobre a possibilidade de continuação das atividades em diferentes universidades públicas. Está, hoje, em discussão a nova proposta do governo, o projeto "Future-se", que justamente coloca como única perspectiva de futuro para o ensino superior a incorporação de elementos mercadológicos e neoliberais que, aos poucos, pretende cobrar por serviços que deveriam ser públicos e universais. A própria existência crescente de empresas Jr. nas universidades já coloca um outro sentido sobre o que seria estar no ensino superior. Seria, então, a inserção nesses espaços uma forma de democratização do conhecimento ou uma democratização de produção de mais-valia?

No contexto do mundo econômico atual, o capitalismo neoliberal, através de estratégias político-econômicas muito sutis e de uma lógica mais depurada a partir da racionalidade instrumental pretensamente hegemônica, tornou-se perverso para as classes sociais mais desprotegidas e historicamente marginalizadas, causando uma verdadeira inversão na ordem dos embates políticosociais. Ou seja, a regra dos não proprietários, que em tempos anteriores era lutar para não serem explorados pelo patrão, hoje, salvo exceções, é lutar para que se consiga um lugar no sistema de exploração da força de trabalho, que, cada vez mais, se transforma em um verdadeiro turbilhão da concorrência e da luta por um emprego, não importando a qualidade e condições de remuneração do mesmo (ZITKOSKI, 2007, p. 08).

Com isso, as universidades têm enfrentado uma desvalorização tanto do governo quanto da sociedade. Na luta pela sobrevivência, a ciência, a pesquisa e o ensino superior não são vistos como garantia de aumento de renda, ao contrário. Parte da opinião pública considera os gastos do Estado para esse setor como um desperdício, algo que deveria ser realocado para outros setores, em tese, mais produtivos economicamente. Ainda, há uma diminuição do interesse de estudo em inúmeras áreas, principalmente de humanas, e um incentivo a cursos rápidos e técnicos de qualificação para o mercado de trabalho. De modo que o tempo para reflexão e busca de alternativas sociais tem sucumbido à busca de um lugar no mercado ou em alternativas de complementação de renda e trabalho informal precarizado.

\section{DISPUTA DISCURSIVA: O (CON) TEXTO PRÁXIS}

O que ocorre quando às ideias são transformadas em propriedade? Bens materiais há muito têm sido alvo de discussões filosóficas, jurídicas, econômicas e sociais. A propriedade privada adquiriu um carácter sagrado de modo que frases como "propriedade é roubo" são vistas com horror e desconfiança. Hoje, sobretudo no meio acadêmico, ideias e reflexões são constantemente transformadas em propriedade, "o conceito de propriedade intelectual está entranhado na psicose coletiva ainda mais fundo que o conceito de propriedade material" (COLETIVO CRIMETHINC, 2001, p. 201). Ora, em uma concepção polissêmica de discurso, é impossível atribuir uma ideia a apenas uma pessoa. Ainda, outro perigo dessa obsessão é seguir ortodoxamente o suposto dono de 
uma ideia, elaborando uma cadeia hierárquica entre quem inventa, quem ensina e quem aprende. Desse modo, um coletivo que pretende uma autogestão e uma educação popular não deveria disseminar propriedades intelectuais como produtos a serem apreendidos e refletidos em uma prova. Mas é isso que o Práxis, muitas vezes, faz. Professores preparam as aulas. Professores detém a maior parte do turno de falas. Alunos entram e saem do coletivo sem que praticamente nada se altere nas aulas.

Os alunos vêm em busca de um cursinho. São 15, 16, 20, 40 anos de formação em um molde ocidental moderno burguês colonizado de vida, alguns meses de aula mal conseguem respingar rebeldia. E quando ela atinge algum ponto sensível de nós, o que fazer? Todos querem entrar na universidade, a promessa de uma melhora de vida soa como um sonho. Precisamos de comida, abrigo, amor. A questão é: aprendemos sobre isso na escola? O que de fato aprendemos no Práxis?

\begin{abstract}
Não há nada que mais contradiga e comprometa a emersão popular do que uma educação que não jogue o educando às experiências do debate e da análise dos problemas e que não Ihe propicie condições de verdadeira participação. Vale dizer, uma educação que longe de se identificar com o novo clima para ajudar o esforço de democratização, intensifique a nossa inexperiência democrática, alimentando-a (FREIRE, 1999, p. 93).
\end{abstract}

No entanto, minha visão é de uma educadora um tanto quanto sonhadora e iludida de estar fazendo alguma diferença. Quanto ao Práxis, o projeto do Coletivo traz algumas concepções que nos ajudam a entender sob que noções ele se constrói. "Nossa opção político-pedagógico nos moldes libertários e autônomos da educação popular nos definiu também como um espaço que privilegia a autonomia e a democracia entre os envolvidos com o projeto (2017)". Os termos centrais, passam a ser, então, libertação e autonomia. Em uma pedagogia libertadora, "todos os sujeitos são responsáveis pela construção de um conhecimento democrático, solidário, inclusivo e libertário" (PROJETO PRÁXIS, 2017). A autonomia é desenvolvida, portanto, pela autogestão do sujeito com o coletivo e com si próprio. "A autogestão é, assim, conteúdo e método; resumo tanto do objetivo pedagógico quanto do político" (PROJETO PRÁXIS, 2017). Nesse ponto, uma pergunta vem à mente: o que a gestão conhece sobre o trabalho que precisa gerir? Ora, em uma prática autogestionada, ela conhece tudo. $O$ educador é coordenador, ao passo que é faxineiro, técnico, porteiro, decorador, e tantas profissões quanto forem necessárias.

Contudo, a autogestão do Práxis se apresenta de um modo diferenciado e, em parte, contraditório. O Coletivo é vinculado a UFSM e, assim, é dependente financeiramente e se vê obrigado a seguir o jogo institucional. Com isso, a autogestão do Coletivo é híbrida, institucionalizada, ou seja, "um espaço institucional definidor das relações sociais contemporâneas, produtor de sujeitos e locus de mediações sociais e políticas" (SILVA, 2011 p. 335). Tal hibridização tem estado presente em outros movimentos sociais e se apresenta como uma espécie de característica dos mesmos frente a atual conjuntura. 
Hoje, vivemos o que alguns sociólogos chamam novos movimentos sociais. Desse modo, são colocadas em pauta não só questões de classe, mas também identitárias, ao passo que a luta "anti-sistema" tem estado cada vez mais sistematizada, institucionalizada. Desde a primeira eleição de um presidente esquerdista pelo Partido dos Trabalhadores, em 2002, concepções em parte subversivas ou opositoras têm buscado atingir seus interesses dentro do próprio jogo político que os subjuga, levando a uma certa incorporação de ações de movimentos sociais para instituições. Um exemplo disso é o debate sobre cotas nas universidades que ascendeu e conseguiu garantir alguns direitos ao longo do início do séc. XXI.

Com isso, a práxis democrática ascende nos próprios modos de reinvindicações política de modo que até mesmo o Estatuto do Práxis incorpora tais ideias: "É direito do educando de participar da Assembleia Geral com igual poder de voz e voto dos educadores e demais participantes". Por essa razão, as assembleias, ou reuniões gerais, constituem o principal meio de deliberações e do fazer democrático. Uma vez por semana os educadores se encontram e debatem acerca das pautas elencadas pelos próprios participantes. Ainda, uma vez por mês, ocorre o diálogo de educadores/educandos para que possam ser trocadas experiências e sugestões sobre o andamento do coletivo. Além disso, está disponível na coordenação uma caixinha para recados diversos, lidos em nas assembleias semanais.

Esses processos podem ser vistos como uma forma provisória e plural de coexistência. Um exercício de corpos e presenças que procura instigar um certo pertencimento geográfico e linguístico (BUTLER, 2018). De modo que:

a autonomia vai se constituindo na experiência de várias, inúmeras decisões, que vão sendo tomadas (...). A autonomia, enquanto amadurecimento do ser para si, é processo, é vir a ser. (...) É nesse sentido que uma pedagogia da autonomia tem de estar centrada em experiências estimuladoras da decisão e da responsabilidade, vale dizer, em experiências respeitosas da liberdade (FREIRE, 1996, p. 107).

Nesse exercício de "autonomia" e "liberdade", espera-se que seja possível alcançar a "emancipação". O Práxis, enquanto um coletivo autogestionário de educação popular, incorpora esse projeto emancipatório das massas, diferente de uma educação massificadora, produtora das massas. Bruno, por exemplo, desenvolve a noção de massificação do seguinte modo:

A massificação, embora resultante da universalização, diz respeito à redução da educação às exigências estritas do mercado de trabalho, tanto no que se refere aos conhecimentos por ele requeridos quanto à imposição da disciplina necessária às formas de organização do trabalho e da vida contemporâneos. A massificação, portanto, resulta da ação do capital para reduzir os processos formativos às exigências estritas da reprodução do capital, daí muitas vezes suscitar a apatia dos estudantes ou sua revolta contra os sistemas de ensino (BRUNO, 2011, p. 551). 
Esse processo de massificação também gera uma produção de subjetividades, comportamentos, personalidades. São discursos que se combinam produzindo culturas, ideologias, narrativas, pedagogias, ciências, currículos. Além disso, esses discursos também criam relações de poder em que cada sujeito passa por uma identificação, uma produção de identidade com certos locais dessa relação. Ainda, se tratando dos jogos de poder e do currículo massificado, se faz necessária uma discussão sobre o material didático a ser usado em sala de aula uma vez que "o currículo do ensino brasileiro é determinado pelo livro didático, não o contrário" (CORBUCCI, 2011, p. 596). Sob o ponto de vista do Práxis, sob o signo da autonomia, cada educador cria seu próprio material didático, sendo disponibilizado recurso para a impressão de polígrafos, se assim desejar.

Além do já exposto, é desenvolvida, no Coletivo Práxis, uma tentativa de prática interdisciplinar e integrada. Percebo os "aulões" promovidos pelo coletivo como um exemplo disso. Todas as sextas-feiras são promovidas aulas abertas sobre temas variados, normalmente com a presença de educadores de diferentes disciplinas. Já foram trazidos temas como: reforma agrária, moradia e direito à cidade, aborto, América Latina, Transantropologia, mulheres na ciência etc. Tais atividades são muito ricas para os próprios educadores que as promovem, uma vez que se faz necessário o diálogo, a troca, a pesquisa, a colaboração, elementos fundamentais da formação docente. Assim, o coletivo quebra a noção curricular da escola básica e se diferencia dos cursinhos particulares que concentram seu "ensino" em memorização, chegando a criar músicas e macetes para que o aluno decore e pense estar aprendendo.

Cabe, também, aqui uma reflexão sobre a origem dos cursinhos populares, uma onda que surge no país na virada do século como uma forma de democratização do ensino. Cícero de Oliveira, antigo educador do Práxis, desenvolve um estudo sobre o Coletivo e os cursinhos populares e os entende como movimentos sociais urbanos. Para o autor (2008, p. 158), "os chamados cursos pré-vestibulares populares (CPVP) constituem um dos maiores movimentos educacionais da história recente do campo educacional brasileiro".

No entanto, o que difere o Práxis de outros cursinhos pré-vestibulares é que o curso Práxis se reconhece enquanto movimento social. "Práxis enquanto um coletivo que atua tanto na frente de capacitação para as avaliações pré-universitárias, quanto na tentativa de construir formas e referências de educação que sejam diferentes do modelo formal de ensino" (PROJETO PRÁXIS, 2017). Ao utilizar a autogestão e possuir uma relativa autonomia institucional o Coletivo rearticula a ordem de discurso hegemônica de hierarquia, liderança, empreendedorismo. Contudo, "a ordem de discurso rearticulada é contraditória: elementos autoritários coexistem com elementos democráticos e igualitários" (FAIRCLOUGH, 2001, p. 124). Com isso, o Práxis se coloca com um local e agente de disputa discursiva, inscrevendo suas ações nas arenas sociais, políticas, educacionais, econômica, culturais e históricas.

\section{ALGUMAS CONCLUSÕES POSSÍVEIS}

Desde o surgimento da noção de propriedade privada e da dominação de um ser humano sobre outro, certas mulheres e homens passaram a ter sua vida, ou parte dela, 
escravizada. Seja no modelo escravocrata, feudal ou capitalista, o corpo humano e sua força produtiva são transformados em mercadorias pertencentes a quem detém os meios de produção. Tal modelo se perpetua ao longo dos séculos pelo seu modelo de gestão que se renova, transforma, agrega e chega a se dizer, por vezes, democrático, mas que não modifica sua estrutura básica de hierarquia.

Dito isso, o texto Práxis se apresenta como uma produção discursiva hibridizada em que a educação popular e autogestão são ressignificadas. Em uma tentativa de quebra de hierarquia e de modificação de relações de poder, o Práxis articula sua gestão de modo a promover uma autonomia, contudo, uma autonomia diferente daquela defendida pelo ideário liberal, constituindo, assim, seu contexto como arena de negociação/disputa discursiva democrática/neoliberal. Tal fato representa uma mudança social a partir do discurso, uma vez que, conforme Fairclough (2001, p. 127), "a mudança envolve formas de transgressão, o cruzamento de fronteiras, tais como a reunião de convenções existentes em novas combinações, ou a sua exploração em situações que geralmente as proíbem".

No entanto, segundo o autor (2001, p. 128), "a mudança deixa traços nos textos na forma de co-ocorrência de elementos contraditórios ou inconsistentes, mesclas de estilos formais e informais, vocábulos técnicos e não técnicos." Isso ajuda a explicar a visão do Coletivo como uma espécie de "colcha de retalhos". Como um local de disputa onde a cada momento de interação se põe em jogo relações de poder, sendo o discurso e a educação campos de força que transbordam e escapam. Como momentos de interação em que o próprio sujeito e o coletivo se colocam em processo e se produzem e modificam, levando consigo toda uma sociedade e sua lógica.

Artigo recebido em: 02/12/2019 Aprovado para publicação em: 05/03/2020

\title{
SELF-MANAGEMENT AND NEOLIBERAL DISCOURSES IN EDUCATION: THE CON(TEXT) PRÁXIS
}

\begin{abstract}
This work is part of a research developed during the Specialization Course in Educational Management, of the Federal University of Santa Maria (UFSM). Besides this, it is an attempt to reread the practice of self-management, from the current neoliberal context in order to understand the discourses produced about self-management in the context of the Coletivo Práxis de Educação Popular. Práxis is a collective linked to UFSM that acts as a social movement of popular education and is self-managed by its components. Therefore, a discursive analysis was performed in documents such as the Statute and the Collective Project as well as in the collective socio-politicaldiscursive practices, understanding the discourse as a constructive practice of world significance. Thus, Práxis presents itself as a hybridized discursive production in which education and selfmanagement are re / signified in in a democratic/neoliberal discursive negotiation/dispute.
\end{abstract}

KEYWORDS: Self-management. Education; Neoliberalism. Práxis. 


\section{AUTOGESTIÓN Y DISCURSOS NEOLIBERALES EN LA EDUCACIÓN: EL CON(TEXTO) PRÁXIS}

RESUMEN: Este trabajo es parte de una investigación desarrollada durante el Curso de Especialización en Gestión Educativa de la Universidad Federal de Santa María (UFSM). Además, se configura como un intento de releer la práctica de la autogestión, desde el contexto neoliberal actual para comprender los discursos producidos sobre la autogestión en el contexto de lo Coletivo Práxis de Educação Popular. Práxis es un colectivo vinculado a UFSM que actúa como un movimiento social de la educación popular y es autogestionado por sus componentes. Con este fin, se realizó un análisis discursivo en documentos como el Proyecto del Colectivo y en las prácticas colectivas sociopolíticas discursivas, entendiendo el discurso como una práctica constructiva del significado del mundo. Por lo tanto, Praxis se presenta como una producción discursiva hibridada en la que la educación y la autogestión se re / significan frente a una negociación / disputa discursiva democrática / neoliberal.

PALABRAS CLAVE: Autogestión. Neoliberalismo. Educación. Práxis.

\section{REFERÊNCIAS}

ALMEIDA, Leandro Viana de. Pré-vestibulares populares: estratégia de acesso dos excedentes à educação superior. 2016. Dissertação (Mestrado em Educação) Universidade Federal de Goiás, Goiânia, 2016.

BAKUNIN, Michael A. Textos Anarquistas. Seleção e notas de Daniel Guérin; trad. Zilá Bernd. Porto Alegre, L\&PM, 1999.

BOBBIO, Norberto. Estado, Governo e Sociedade. 21 ed.- Revista atualizada, Rio de Janeiro/ São Paulo Paz e Terra, 2018.

BORDIGNON, Genuíno. Gestão da educação no município: sistema, conselho e plano. São Paulo, Editora e Livraria Instituto Paulo Freire, 2009.

BRASIL. Constituição (1988). Constituição da República Federativa do Brasil. Brasília, DF, Senado Federal, Centro Gráfico, 1988.

BRASIL. Ministério de Educação e Cultura. LDB - Lei no 9394/96, de 20 de dezembro de 1996. Estabelece as diretrizes e bases da Educação Nacional. Brasília, MEC, 1996.

BRASIL. Lei n. 13.005, de 25 de junho de 2014. Aprova o Plano Nacional de Educação - PNE e dá outras providências. Diário Oficial da União, Brasília, DF. 26 jun 2014.

BRUNO, Lúcia. Educação e desenvolvimento econômico no Brasil. Revista Brasileira de Educação. Rio de Janeiro, ANPEd, v. 16, n. 48, set./dez.2011. 
BUTLER, Judith. Corpos em aliança e a política das ruas: notas para uma teoria performativa de assembleia. Tradução Fernanda Siqueira Miguens; revisão técnica Carla Rodrigues. - $1^{\circ}$ ed.- Rio de Janeiro, Civilização Brasileira, 2018.

COLETIVO CRIMETHINC. Dias de guerra, noites de amor. 2001. Disponível em: https://we.riseup.net/assets/402768/diasdeguerra.pdf. Acesso: jun. 2019.

COLETIVO CRIMETHINC. Da democracia à liberdade. 2017. Disponível em: https://we.riseup.net/assets/413250/democracia-livro-laser.pdf. Acesso: jun. 2019.

COLETIVO PRÁXIS. Projeto. Santa Maria: Práxis, 2017.

CORBUCCI, Paulo Roberto. Dimensões estratégicas e limites do papel da educação para o desenvolvimento brasileiro. Revista Brasileira de Educação, Rio de Janeiro, ANPEd, v.16, n. 48 , set./dez.2011.

CUNHA, Célio da. Sociedade do Conhecimento: quais e que conhecimentos são mais relevantes: In: Fórum latino-americano de educação superior. São Carlos: Pixel, 2015.

FAIRCLOUGH, Norman. Discurso e mudança social. Brasília, Editora Universidade de Brasília, 2001.

FREIRE, Paulo. Educação como prática da liberdade. 23a_ ed. Rio de Janeiro: Paz e Terra, 1999.

FREIRE, Paulo. Pedagogia da Autonomia: saberes necessários à prática educativa. São Paulo: Paz e Terra, 1996.

FREITAS, Luiz Carlos de. A reforma empresarial da educação: nova direita, velhas ideias. $1^{\circ}$ ed. São Paulo, Expressão Popular, 2018.

LÜCK, Heloísa. Perspectivas da gestão escolar e implicações quanto à formação de seus gestores. Em aberto, Brasília, v. 17, no 72, 2000.

MALATESTA, Errico. Sob um regime de Ditadura "Proletária". A justiça segundo os Comunistas Ditatoriais. In: Errico Malatesta: Anarquistas, Socialistas e Comunistas. São Paulo, Intermezzo/Imaginário, 2014.

OLIVEIRA, Cícero Santiago de. O Práxis - coletivo de educação popular e a universidade em movimento. Santa Maria, UFSM, 2008.

PEREIRA, João Márcio Mendes. As ideias do poder e o poder das ideias: o Banco Mundial como ator político-intelectual. Revista Brasileira de Educação, Rio de Janeiro, ANPEd. v. 19, n. 56, jan-mar, 2014. 
PERONI, Vera. Implicações da relação público privado para democratização da educação no Brasil. In: Diálogos para redefinição do papel do estado nas fronteiras entre o público e o privado na educação. São Leopoldo, Oikos, 2015.

SILVA, Rodrigo M. Dias da. A escola e as normas em conflito: um ensaio sobre a educação institucionalizada e direitos humanos. Política \& Sociedade: Revista de Sociologia Política, Florianópolis, UFSC, 2011.

ZITKOSKI, Jaime José. Educação Popular e Pós Modernidade: um olhar em tempos de incerteza. Cadernos IHU, São Leopoldo, ano 5. n. 21. 2007.

Themis Karine Dutra MeneGazZI: Formada em Letras - licenciatura em Língua portuguesa e Inglesa pelo Centro Universitário Franciscano (2017). Especialista em Gestão Educacional pela Universidade Federal de Santa Maria (2019). Acadêmica do curso de Ciências Sociais também pela UFSM. Bolsista no Coletivo Práxis de Educação Popular, projeto de extensão da UFSM. Pesquisadora no Grupo de Pesquisa "RIZOMA - Políticas, Currículo e Educação" /CNPq.

Orcid: https://orcid.org/0000-0002-5461-1726

E-mail: themismenegazzii@gmail.com

JoACIR MARques dA Costa: Professor Adjunto na Universidade Federal de Santa Maria UFSM. Doutor em Educação. Mestre em Educação. Especialista em Gestão Educacional. Licenciado em Matemática. Líder do Grupo de Pesquisa "RIZOMA - Políticas, Currículo e Educação" /CNPq. Pesquisador nos grupos de pesquisa "Elos", "GEPPGE - Políticas Públicas e Gestão Educacional" e "Tuna - Gênero, Educação e Diferença". Professor/Orientador no Programa de Pós-Graduação em Políticas Públicas e Gestão Educacional (PPPG/UFSM).

Orcid: https://orcid.org/0000-0002-6099-7186

E-mail:mc.joacir@smail.com

Este periódico utiliza a licença Creative Commons Attribution 3.0, para periódicos de acesso aberto (Open Archives Iniciative - OAI). 